\title{
3D Echocardiography - A Useful Method for Cardiovascular Risk Assessment in End-Stage Renal Disease Patients
}

\author{
Magdaléna KOVÁŘOVÁ ${ }^{1}$, Zuzana ŽILINSKÁ ${ }^{\mathbf{1 , 2}}$, Ján PÁLEŠ ${ }^{1}$, Zuzana KUŽMOVÁ ${ }^{\mathbf{1}}$, \\ Andrea GAŽOVÁ ${ }^{3}$, Juraj SMAHA ${ }^{1}$, Martin KUŽMA ${ }^{1}$, Peter JACKULIAK ${ }^{1}$, Viera \\ ŠTVRTINOVÁ ${ }^{4}$, Ján KYSELOVIČ ${ }^{1}$, Juraj PAYER ${ }^{1}$
}

${ }^{1} 5^{\text {th }}$ Department of Internal Medicine, Comenius University Faculty of Medicine, University Hospital Bratislava, Bratislava, Slovakia, ${ }^{2}$ Department of Urology with The Centre for Kidneytransplantation, Comenius University Faculty of Medicine, University Hospital Bratislava, Bratislava, Slovakia, ${ }^{3}$ Institute of Pharmacology and Clinical Pharmacology, Faculty of Medicine in Bratislava, Comenius University, Bratislava, Slovakia, ${ }^{4} 1^{\text {th }}$ Department of Internal Medicine, Comenius University Faculty of Medicine, University Hospital Bratislava, Bratislava, Slovakia

Received May 4, 2021

Accepted September 29, 2021

\section{Summary}

Patients with chronic kidney disease (CKD) have an increased risk of premature mortality, mainly due to cardiovascular causes. The association between hemodialysis and accelerated atherosclerosis has long been described. The ankle-brachial index (ABI) is a surrogate marker of atherosclerosis and recent studies indicate its utility as a predictor of future cardiovascular disease and all-cause mortality. The clinical implications of ABI cut-points are not well defined in patients with CKD. Echocardiography is the most widely used imaging method for cardiac evaluation. Structural and functional myocardial abnormalities are common in patients with CKD due to pressure and volume overload as well as non-hemodynamic factors associated with CKD. Our study aimed to identify markers of subclinical cardiovascular risk assessed using $\mathrm{ABI}$ and $2 \mathrm{D}$ and $3 \mathrm{D}$ echocardiographic parameters evaluating left ventricular (LV) structure and function in patients with end-stage renal disease (ESRD) (patients undergoing dialysis), patients after kidney transplantation and non-ESRD patients (control). In ESRD, particularly in hemodialysis patients, changes in cardiac structure, rather than function, seems to be more pronounced. 3D echocardiography appears to be more sensitive than 2D echocardiography in the assessment of myocardial structure and function in CKD patients. Particularly 3D derived end-diastolic volume and 3D derived LV mass indexed for body surface appears to deteriorate in dialyzed and transplanted patients. In 2D echocardiography, myocardial mass represented by left ventricular mass/body surface area index (LVMI) appears to be a more sensitive marker of cardiac structural changes, compared to relative wall thickness (RWT), left ventricle and diastolic diameter index (LVEDDI) and left atrial volume index (LAVI). We observed a generally favorable impact of kidney transplantation on cardiac structure and function; however, the differences were non-significant. The improvement seems to be more pronounced in cardiac function parameters, peak early diastolic velocity/average peak early diastolic velocity of mitral valve annulus (E/e'), 3D left ventricle ejection fraction (LV EF) and global longitudinal strain (GLS). We conclude that ABI is not an appropriate screening test to determine the cardiovascular risk in patients with ESRD.

\section{Key words}

End-stage chronic kidney disease - Hemodialysis - Kidney transplantation • Ankle-brachial index $\bullet$ Echocardiography

\section{Corresponding author}

Peter Jackuliak, $5^{\text {th }}$ Department of Internal Medicine, Comenius University Faculty of Medicine in Bratislava, University Hospital Bratislava, Ružinovská 6, 82606 Bratislava, Slovakia. Email: peter.jackuliak@fmed.uniba.sk

\section{Introduction}

Chronic kidney disease (CKD) is defined according to Kidney Disease Improving Global Outcomes (KDIGO) 2012 guidelines as a functional or structural kidney abnormity, lasting for at least 3 months 
and classified according to ethology, glomerular filtration rate (GFR) and/or albuminuria (Table 1) (Andrassy 2013). Due to diagnostic difficulties, there is no uniformly agreed definition of end-stage CKD. However, the presence of an estimated GFR $<15 \mathrm{ml} / \mathrm{min} / 1.73 \mathrm{~m}^{2}$ is considered and end-stage is a condition in which renal function is reduced to such an extent that it leads to the need for regular long-term dialysis or kidney transplantation.

Patients with $\mathrm{CKD}$, including end-stage, are at greater risk of cardiovascular diseases and death compared with the general population. Even a minor reduction in the GFR appears to be an independent risk factor for causing cardiovascular abnormalities. This elevated risk is in part due to a higher incidence of CKDrelated risk factors as is atherosclerosis, anemia, presence of uremic toxins, altered calcium-phosphate metabolism and over-activity of the renin-angiotensin-aldosterone system. These pathological conditions lead to remodeling of the myocardium and blood vessels, thus resulting in atherosclerosis and arterial stiffness, ischemic heart disease, cardiomyopathy, heart failure, simultaneously with rapid renal progression to end-stage status. Patients with CKD and cardiovascular diseases had a three to thirty-time higher risk of mortality as compared to the general population. At each stage of CKD, the risk of cardiovascular mortality is several-fold higher than the risk of progression to end-stage CKD and associated with more than $50 \%$ of the deaths in CKD patients (Matsushita et al. 2015).

Patients with end-stage CKD have a high prevalence of peripheral artery disease, an important manifestation of systemic atherosclerosis and ankle- brachial index (ABI) is a common noninvasive and useful screening test for detecting it (Chen et al. 2012). Structural and functional myocardial abnormalities, mostly LV hypertrophy, have been proven to correlate with high cardiovascular morbidity and mortality, and are common in patients with CKD due to pressure and volume overload (Byoung-Geun et al. 2010). Patients enrolled in a chronic hemodialysis program differ from the general population by periodic changes of hydration and by the presence of a low-resistance arteria-venous shunt and arterial hypertension (Maillou et al. 1998). These clinical statuses can impact a variety of echocardiographic parameters (Malík et al. 2018) as left ventricular (LV) structure (concentric hypertrophy) and function (decreased ejection fraction), along with left atrial (LA) size (increased diameter) are associated with faster renal function decline (Chen et al. 2011). In endstage CKD patients, symptoms of heart failure might be difficult to differentiate from the symptoms of hyper hydration (Malík et al. 2018). Therefore, the evaluation of echocardiographic parameters might help to determine the risk and prognosis of cardiovascular and chronic kidney diseases.

One of the most important treatment modalities for end-stage patients is kidney transplantation and heart failure post transplantation remains a major contributor to cardiovascular (CV) related hospitalizations (Deferrari et al. 2021, Rangaswami et al. 2019). Another important treatment modality is hemodialysis. However, in patients on hemodialysis, the high prevalence of coronary heart disease and ventricular hypertrophy has been described due to accelerated atherosclerosis and continuous reduction in LV function as renal function declines.

Table 1. Kidney Disease Improving Global Outcomes (KDIGO) 2012 Guidelines Classification (Andrassy, 2013)

\begin{tabular}{lcc}
\hline GFR Stages & GFR ( $\left.\mathbf{m l} / \mathbf{m i n} / \mathbf{1 . 7 3} \mathbf{~ m}^{\mathbf{2}}\right)$ & Terms \\
\hline$G 1$ & $>90$ & Normal or high \\
$G 2$ & $60-89$ & Mildly decreased \\
$G 3 a$ & $45-59$ & Mildly to moderately decreased \\
$G 3 b$ & $30-44$ & Moderately to severely decreased \\
$G 4$ & $15-29$ & Severely decreased \\
$G 5$ & $<15$ & Kidney failure \\
\hline Albuminuria Stages & AER or $\mathbf{A C R}(\mathbf{m g} / \mathbf{2 4 h}$ or $\mathbf{~ m g / g )}$ & Terms \\
\hline$A 1$ & $<30$ & Normal to mildly increased \\
$A 2$ & $30-299$ & Moderately increased \\
$A 3$ & $\geq 300$ & Severely increased \\
\hline
\end{tabular}

$A C R$, albumin-to-creatinine ratio; AER, albumin excretion rate (24 hours) 
Importantly, the risk of developing pulmonary hypertension also rises proportionately to the duration of hemodialysis. In contrast to dialysis, renal transplantation can help prevent the progression of pathological cardiovascular processes. Renal transplantation can potentially reverse myocardial damage that is thought to result from prolonged exposure to uremic toxins and improve LV systolic function (Bhatti el al. 2016).

Our study aimed to detect markers of subclinical cardiovascular risk as assessed with $\mathrm{ABI}$ and conservative and novel echocardiographic parameters evaluating LV structure and function in patients with endstage kidney disease undergoing dialysis, after kidney transplantation and non-end-stage patients (control).

\section{Patients and methods}

\section{Study participants}

From October 2019 to March 2020, a crosssectional study was conducted. Diagnosis of stages (G1-G5) of kidney disease was established according to the most recent KDIGO guidelines (Andrassy, 2013), see Table 1. All study procedures were reviewed and approved by a local ethical committee. Each patient before any study procedure signed informed consent. Study participants were divided into 3 subgroups:

1. Patients undergoing dialysis with estimated glomerular filtration rate (eGFR) of less than $15 \mathrm{ml} / \mathrm{min} / 1.73 \mathrm{~m}^{2}$ before kidney transplantation (G5D),

2. Patients who were at least 1 year after kidney transplantation and according to eGFR are in stages G2-3 KDIGO (G2-3T),

3. Subjects selected from age- and gender-matched outpatients who were examined at the preventive examination and were confirmed not higher than G1 - G2 stages according to KDIGO classification (control group).

G1 and G2 are defined as CKD only in case of moderately or severely increased albuminuria (Bhatti et al. 2016). In our control group only mildly increased albuminuria was detected in several patients.

Patients with previous confirmation of heart failure diagnosis were not included in the analysis. Patients within subgroup G5D and G2-3T were regularly followed at the Department of Urology with the Center for Kidney Transplantation of University Hospital,
Bratislava. Their chronic diagnoses were consistently stable and they were in a good clinical condition and documented in medical records. Patients in the control group were selected from the out-patient clinic at the $5^{\text {th }}$ Department of Internal medicine of University Hospital, Bratislava.

\section{Clinical and laboratory measures}

Clinical parameters, such as age, gender, weight, height, systolic/diastolic blood pressure, heart rate and the use of medications including aspirin/other antiplatelet agents, anticoagulant therapy, statins, angiotensinconverting enzyme inhibitors/ angiotensin II receptor blockers, calcium channel blockers, beta-blockers, diuretics, immunosuppressive therapy were recorded. The subject was considered to have hypertension if the systemic blood pressure was more than $140 \mathrm{mmHg}$ or diastolic blood pressure was more than $90 \mathrm{mmHg}$ or if the patient was currently using antihypertensive agents. Body mass index (BMI) was calculated as (weight $[\mathrm{kg}] /$ height $\left[\mathrm{m}^{2}\right]$ ). The etiology of CKD was drawn from management records in nephrologists. Blood pressure, heart rate, BMI, ABI measurement and echocardiography were recorded on the same day when the blood samples were taken.

Biochemical parameters, such as blood urea nitrogen, creatinine, cholesterol, triacylglycerols (TAG), low-density lipoprotein (LDL), cholesterol, high-density lipoprotein (HDL), cholesterol were measured by standard kits at a commercial laboratory. Estimated glomerular filtration (eGFR) was calculated using the formula Chronic Kidney Disease, Epidemiology Collaboration. Venous blood was drawn in all subjects in the morning after a 6-hour fasting period into polyethylene tubes without an anticoagulation agent for serum. Serum biochemical parameters were analyzed routinely using an auto-analyzer (Roche Diagnostics $\mathrm{GmbH})$.

\section{ABI (ankle-brachial index)}

Measurements of ABI were obtained using an ABI-form device (boso ABI - system 100, BOSCH + SOHN, Germany), which automatically and simultaneously measures blood pressure in both the arms and the ankles by using an oscillometric method and measurements were performed once for each patient. According to the American Heart Association, normal values for $\mathrm{ABI}$ are between 0.9 and 1.3 (Gerhard-Herman et al. 2017). 


\section{Echocardiography}

All of the echocardiography studies were performed by a single physician using a commercial echocardiography system (Vivid E95, GE Healthcare, Horten, Norway) with a wide bandwidth (1.4-5.2 MHz) matrix-array transducer (4Vc-D, GE Healthcare, Horten, Norway) in the left decubitus position. 3D analysis, including the 3D strain, was performed in real-time by 4D Auto LVQ software (GE Healthcare, Horten, Norway), which was included in the echocardiography system. In dialyzed patients, echocardiography was done at least 24 hours after dialysis to avoid hemodialysis induced myocardial stunning and changes in volume status. LV quantitative analysis was performed in agreement with recommendations of the American Society of Echocardiography (ASE) and the European Association of Cardiovascular Imaging (EACVI) (Lang et al. 2015). From the parasternal long-axis view, the thickness of the interventricular septum (IVS), left ventricle end-diastolic diameter (LVEDD) and $\mathrm{LV}$ posterior wall $(\mathrm{PWd})$ were measured at the enddiastole of the LV using B-mode. LVEDD was indexed to body surface area (BSA) using the DuBois formula (Du Bois, et al. 1916). Relative wall thickness (RWT) was calculated as $2 \times \mathrm{PWd} / \mathrm{LVEDD}$. LV mass was calculated using the cube formula (Lang et al. 2015) from 2D images and indexed to the body surface area LVMI. Left ventricle hypertrophy (LVH) was defined according to the EACVI/ASE guidelines as LVMI $>88 \mathrm{~g} / \mathrm{m}^{2}$ in females and $102 \mathrm{~g} / \mathrm{m}^{2}$ in males (Lang et al. 2015). LVH was classified as concentric if RWT $>0.42$. Left atrial volume was calculated by the disk summation algorithm - bi-plane at end-systole and subsequently indexed to the body surface area (LAVI). LAVI was considered increased if $>34 \mathrm{ml} / \mathrm{m}^{2}$ (Matsushita et al. 2015). Peak early (E) and late (A) diastolic velocity and the E/A ratio were assessed from the mitral flow velocity pattern with the pulse Doppler method. Average peak early diastolic velocity of mitral valve annulus $\left(\mathrm{e}^{\prime}\right)$ were obtained from the septal and lateral sides of the mitral annulus in the apical four-chamber view with Doppler tissue imaging. The $\mathrm{E} / \mathrm{e}^{\prime}$ ratio was calculated to estimate $\mathrm{LV}$ filling pressures. LV diastolic function was evaluated from E/A ratio, E/e', LAVI and tricuspid regurgitation velocity according to the current guidelines (Nagueh et al. 2016). Right ventricular systolic pressure (RVSP) was derived from peak tricuspid regurgitation velocity by Bernoulli equation and estimation of right atrial pressure from inferior vena cava diameter and its collapsibility (Rudski, et al. 2010). Real-Time 3D echocardiographic imaging was performed from the cardiac apex by single beat acquisition or multi-beat acquisition (triggered by ECG) using 2 to 3 consecutive cardiac cycles during a single breath-hold. Resolution and frame rate were optimized by adjusting the depth and the sector width while including entire LV cavity within the pyramidal volume. From the recorded real-time 3D images, end-systolic and enddiastolic LV volumes, ejection fraction, LV mass and 3D global longitudinal strain were calculated semiautomatically (three points selection with tracing adjustments) by 4D Auto LVQ software. LV mass and end-diastolic volume (EDV) were indexed to BSA. LV dilatation was defined according to the ASE/EACVI guidelines recommendation for $3 \mathrm{D}$ echocardiographic LV volumes measurement as follows: upper limits of LV EDV $79 \mathrm{ml} / \mathrm{m}^{2}$ for men and $71 \mathrm{ml} / \mathrm{m}^{2}$ for women (Lang et al. 2015). The same LV mass cut off values for $\mathrm{LVH}$ were used for $3 \mathrm{D}$ as for the $2 \mathrm{D}$ measurement.

\section{Statistical analysis}

For statistical analysis, Analyze-it $\AA$ software version 4.91.3 (The Tannery, Leeds, United Kingdom) was used. Continuous variables were expressed as mean \pm standard deviation (SD). Before statistical analysis, we excluded values that were greater/lesser than $+/-3$ SD. The Shapiro-Franca test was used to assess the normality of the distribution of the monitored parameters. For individual comparisons between groups, we used Student's t-test and Mann-Whitney test depending on the normality of the distribution of specific data. For specific measures (echocardiography and ABI) we used ANOVA analysis to compare individual groups. We used univariate analysis and logistic regression to assess individual correlations. We considered $\mathrm{p} \leq 0.05$ values to be significant differences.

\section{Results}

\section{Clinical characteristics of study participants}

The study population consisted of 41 patients (19 women/22 men) with 19 G5D and 22 G2-3T subjects. Subgroup G5D consisted of 11 men and 8 women; average age $53.95 \pm 10.45$ years, undergoing dialysis with eGFR less than $15 \mathrm{ml} / \mathrm{min} / 1.73 \mathrm{~m}^{2}$. Subgroup G2-3T consisted of 11 men and 11 women with average age $46.7 \pm 13.05$ years. A control group involved 41 persons (23 women and 18 men) with average age $55.24 \pm 13.93$ years (see all characteristics of the study groups in Table 2). 
The etiology of end-stage kidney disease is presented Fig. 1. There are no significant differences between the prescribed drugs, including aspirin/other antiplatelet agents, anticoagulant therapy, statins, angiotensin-converting enzyme inhibitors/angiotensin II receptor blockers, calcium channel blockers and betablockers between the G5D and G2-3T groups. None of the patients took diuretics. Patients in the G2-3T group received standard recommended immunosuppressive therapy.
Biochemical results

Table 2 summarized the relevant anthropometric and biochemical characteristics. The eGFR in G5D was significantly lower in comparison to G2-3T and control group $(p=<0.0001)$, and no significant differences in blood glucose levels, total cholesterol, HDL cholesterol, LDL cholesterol and TAG between subgroups.

\section{Conventional 2D echocardiography}

In the control group, $3(7.3 \%)$ cases of $\mathrm{LV}$ hypertrophy (defined by the ASE/EACVI guidelines)

Table 2. Clinical, anthropometric and biochemical characteristics of G5D, G2-3T and control groups

\begin{tabular}{|c|c|c|c|c|c|c|}
\hline & G5D & G2-3T & Control & $\begin{array}{c}\text { G5G } \\
\text { vs } \\
\text { G2-3T } \\
\text { p-value }\end{array}$ & $\begin{array}{c}\text { G5D } \\
\text { vs } \\
\text { control } \\
\text { p-value }\end{array}$ & $\begin{array}{c}\text { G2-3T } \\
\text { vs } \\
\text { control } \\
\text { p-value }\end{array}$ \\
\hline Number (men/women) & $19(11 / 8)$ & $22(11 / 11)$ & $41(18 / 23)$ & & & \\
\hline Age (years) & $53.95 \pm 10.45$ & $46.73 \pm 13.05$ & $55.24 \pm 13.93$ & 0.1595 & 0.8765 & $0.0145^{*}$ \\
\hline Height $(\mathrm{cm})$ & $171.8 \pm 10.3$ & $171.5 \pm 9.6$ & $170.4 \pm 10.1$ & 0.9894 & 0.9763 & 0.9997 \\
\hline Weight $(\mathrm{kg})$ & $74.93 \pm 15.9$ & $77.7 \pm 17.45$ & $77.21 \pm 17.54$ & 0.6076 & 0.4881 & 0.9989 \\
\hline$B M I\left(k g / m^{2}\right)$ & $25.39 \pm 4.2$ & $26.47 \pm 4.5$ & $26.47 \pm 5.3$ & 0.6731 & 0.5552 & 0.9989 \\
\hline$e G F R\left(\mathrm{ml} / \mathrm{s} / 1,73 \mathrm{~m}^{2}\right)$ & $0.1756 \pm 0.075$ & $1.067 \pm 0.319$ & $1.425 \pm 0.2589$ & $<0.0001 *$ & $<0.0001 *$ & $<0.0001 *$ \\
\hline Glucose (mmol/l) & $5.843 \pm 4.01$ & $5.372 \pm 1.867$ & $6.18 \pm 3.014$ & 0.9661 & 0.8283 & 0.4732 \\
\hline $\operatorname{Urea}(\mathrm{mmol} / \mathrm{l})$ & $14.67 \pm 7.17$ & $8.027 \pm 2.644$ & $5.405 \pm 1.734$ & $<0.0001 *$ & $<0.0001 *$ & 0.9976 \\
\hline Creatinine $(\mu \mathrm{mol} / \mathrm{l})$ & $515.5 \pm 183$ & $155.3 \pm 132$ & $76.57 \pm 15.23$ & $<0.0001^{*}$ & $<0.0001 *$ & 0.9988 \\
\hline Total Cholesterol $(\mathrm{mmol} / \mathrm{l})$ & $5.317 \pm 1.069$ & $4.669 \pm 1.661$ & $4.681 \pm 1.083$ & 0.2565 & 0.9274 & 0.6422 \\
\hline Triacylglycerols (mmol/l) & $1.66 \pm 0.8847$ & $1.704 \pm 0.8864$ & $1.48 \pm 0.83$ & 0.9982 & 0.9938 & 0.9995 \\
\hline LDL-cholesterol (mmol/l) & $3.758 \pm 1.06$ & $3.081 \pm 1.606$ & $3.064 \pm 1.106$ & 0.2045 & 0.8074 & 0.7556 \\
\hline HDL-cholesterol (mmol/l) & $1.436 \pm 0.44$ & $1.461 \pm 0.36$ & $1.455 \pm 0.41$ & 0.9976 & 0.9775 & 0.9285 \\
\hline
\end{tabular}

Data are shown as average \pm standard deviation. P-value by two-way ANOVA test. $C=$ control group, ESRD=end-stage renal disease group; G5D=dialyzed patients group; G2-3T=patients after renal transplantation group; eGFR -estimated Glomerular Filtration Rate

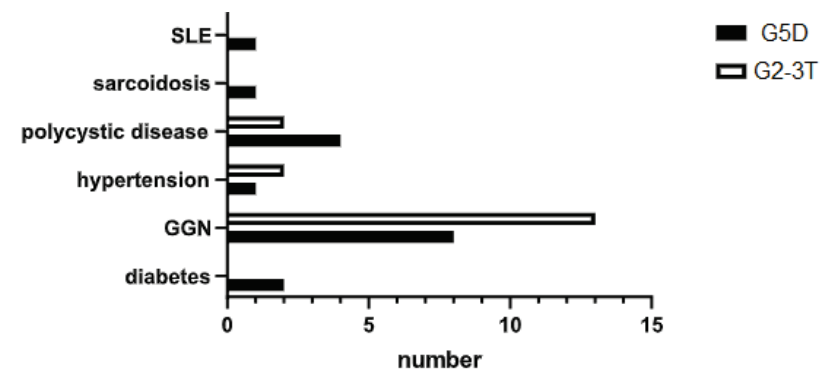

Fig. 1. Etiology of ESRD. GGN - glomerulonephritis; SLE, systemic lupus erythematosus

were recorded. One case of grade 2 diastolic dysfunction and $7(17.1 \%)$ cases of LAVI $>34 \mathrm{ml} / \mathrm{m}^{2}$ were found, no patient had $E / e^{\prime}>14$. Compared to the control group, higher LVMI was observed in G5D group (92.46 \pm 26.51 vs $\left.69.72 \pm 18.95 \mathrm{~g} / \mathrm{m}^{2}, \quad \mathrm{p}=0.0091\right)$, while the difference in G2-3T was non-significant. LV hypertrophy, calculated from LVMI (as defined by ASE/EACVI), was present in 10 G5D patients $(52.6 \%)$ and $8 \quad(36.4 \%) \quad$ G2-3T patients. Concentric LV hypertrophy was present in $3(15.8 \%)$ patients in G5D and $1(4.5 \%)$ patient in G2-3T. No significant differences between groups in LVEDDI, RWT, LAVI, E/e' and RVSP were observed. There were non-significant trends towards higher LVEDDI, LAVI, RWT and E/e' in G5D in comparison to the control group observed. No difference of G2-3T in comparison to the control group was observed. Increased LAVI $\left(>34 \mathrm{ml} / \mathrm{m}^{2}\right)$ was present 
in $12(63.2 \%)$ and $14(63.6 \%)$ patients in G5D and G2-3T, respectively. Diastolic dysfunction of grade $\geq 2$ was present in $4(21.1 \%)$ and $1(4.5 \%)$ patients in G5D and G2-3T, respectively. Increased E/e' $>14$ was found only in $3(15.8 \%)$ patients within G5D. In G2-3T patients, compared to G5D, we observed the general tendency to improved cardiac structure and function parameters - lower mean values of LVEDDI, LVMI, RWT, LAVI, E/e' and RVSP. However, none of these differences were significant; the difference in E/e' was the most pronounced. The results are summarized in Table 3 .

\section{Real-time $3 D$ echocardiography}

LV mass measured with 3D echocardiography was increased only in 1 patient. EDV was significantly higher in G5D in comparison to control group (122.7 \pm 30.96 vs. $89.2 \pm 18.5 \mathrm{ml}, \mathrm{p}=0.0025)$. EDVI and 3D derived LV mass index were higher in both G5D and G2-3T in comparison to control group. No significant between G5D and G2-3T was observed. Dilated LV, defined by EDVI (more than $79 \mathrm{ml} / \mathrm{m}^{2}$ for men and $71 \mathrm{ml} / \mathrm{m}^{2}$ for women) was found in $4(21.1 \%)$ and $3(13.6 \%)$ patients with G5D and G2-3T. LVH derived from $3 \mathrm{D}$ mass (defined as $>88 \mathrm{~g} / \mathrm{m}^{2}$ for women and $>102 \mathrm{~g} / \mathrm{m}^{2}$ for men) was present in 3 patients in each G5D and G2-3T group (15.8\% and $13.6 \%$, respective). The results are shown in Table 4. G2-3T patients in comparison to control group, less negative 3D GLS $(-21.13 \pm 2.62$ vs $-16.4 \pm 4.1 \%, p=0.0039)$, as well as higher EF were recorded, the difference in EF was not significant. There were no significant differences in all
3D echocardiography between G2-3T patients compared to G5D. However, the non-significant trend towards higher LV EF and GLS was observed, indicating possible improvement of LV systolic function after transplantation.

$A B I$

No significant differences in ABI measurements between study subgroups were observed (Table 5).

\section{Discussion}

Despite recent huge advances in medicine, high mortality and morbidity in patients with $\mathrm{CKD}$ remain an important but unresolved issue. Cardiovascular clinical complications are the major cause of mortality and morbidity in patients with CKD. Abnormal geometry and left ventricular function are common in this group of patients and have been shown to correlate with high cardiovascular mortality/morbidity and mortality from any cause. However, it remains a problem to distinguish between symptoms of hyper hydration and symptoms of heart failure in dialysis patients. For this reason, the echocardiographic study plays an important role in assessing the structure and function of the heart, as well as in stratifying the prognostic risk. Generally, renal transplantation can help prevent the progression of pathological cardiovascular processes and potentially reverse myocardial damage that is thought to result from prolonged exposure to uremic toxins and improve LV systolic function.

Table 3. Conventional 2D echocardiographic parameters of left ventricular structure and function in G5D, G2-3T patients compared to control group

\begin{tabular}{|c|c|c|c|c|c|c|}
\hline Parameter & G5D & G2-3T & Control & $\begin{array}{c}\text { G5D } \\
\text { vs } \\
\text { G2-3T } \\
\text { p-value }\end{array}$ & $\begin{array}{c}\text { G5D } \\
\text { vs } \\
\text { control } \\
\text { p-value }\end{array}$ & $\begin{array}{c}\text { G2-3T } \\
\text { vs } \\
\text { control } \\
\text { p-value }\end{array}$ \\
\hline$L V E D D I\left(\mathrm{~mm} / \mathrm{m}^{2}\right)$ & $27.36 \pm 3.294$ & $26.85 \pm 3.169$ & $25.45 \pm 2.295$ & 0.9496 & 0.2045 & 0.4428 \\
\hline$L V M I\left(g / m^{2}\right)$ & $92.46 \pm 26.51$ & $87.25 \pm 19.69$ & $69.72 \pm 18.95$ & 0.8777 & $0.0091 *$ & 0.0542 \\
\hline$R W T$ & $0.3484 \pm 0.10$ & $0.334 \pm 0.06$ & $0.3167 \pm 0.06$ & 0.9208 & 0.5143 & 0.8624 \\
\hline$L A V I\left(\mathrm{ml} / \mathrm{m}^{2}\right)$ & $38.63 \pm 8.35$ & $37.64 \pm 10.50$ & $32.4 \pm 12.5$ & 0.9894 & 0.2389 & 0.3580 \\
\hline$E / e^{\prime}$ & $9.83 \pm 5.18$ & $7.13 \pm 2.27$ & $7.18 \pm 2.0$ & 0.1158 & 0.2171 & $>0.9999$ \\
\hline RVSP (mmHg) & $31.39 \pm 7.212$ & $30.17 \pm 4.97$ & $32.2 \pm 7.6$ & 0.9423 & 0.9805 & 0.7741 \\
\hline
\end{tabular}

Data are shown as average \pm standard deviation. $\mathrm{P}$ value by two-way ANOVA test. $\mathrm{C}=$ control group; G5D=dialyzed patients group; $\mathrm{G} 2-3 \mathrm{~T}=$ patients after renal transplantation group; $\mathrm{E}=$ peak early diastolic velocity; $\mathrm{e}^{\prime}=$ average early diastolic mitral annular velocity; LAVI=left atrial volume index; LVEDDI=left ventricle and diastolic diameter index; LVMI=left ventricular mass/body surface area index; $\mathrm{RVSP}=$ right ventricular systolic pressure; RWT=relative wall thickness 
Table 4. 3D echocardiographic parameters of left ventricular structure and function in G5D, G2-3T patients compared to control group

\begin{tabular}{|c|c|c|c|c|c|c|}
\hline Parameter & G5D & G2-3T & Control & $\begin{array}{c}\text { G5D } \\
\text { vs } \\
\text { G2-3T } \\
\text { p-value }\end{array}$ & $\begin{array}{c}\text { G5D } \\
\text { vs } \\
\text { control } \\
p \text {-value }\end{array}$ & $\begin{array}{c}\text { G2-3T } \\
\text { vs } \\
\text { control } \\
p \text {-value }\end{array}$ \\
\hline$E D V 3 D(\mathrm{ml})$ & $122.7 \pm 30.96$ & $110.7 \pm 30.11$ & $89.2 \pm 18.5$ & 0.5302 & $0.0025^{*}$ & 0.0812 \\
\hline$E D V I 3 D\left(\mathrm{ml} / \mathrm{m}^{2}\right)$ & $65.32 \pm 13.57$ & $58.24 \pm 13.35$ & $46.53 \pm 6.09$ & 0.2795 & $<0.0001^{*}$ & $0.0191 *$ \\
\hline$L V$ mass index $3 D\left(\mathrm{~g} / \mathrm{m}^{2}\right)$ & $80.08 \pm 15.93$ & $78.96 \pm 14.21$ & $62.65 \pm 13.07$ & 0.9954 & $0.0045^{*}$ & $0.0071^{*}$ \\
\hline$E F L V 3 D(\%)$ & $58.05 \pm 6.916$ & $62.18 \pm 4.46$ & $59.15 \pm 5.9$ & 0.1191 & 0.9371 & 0.3454 \\
\hline$G L S 3 D(\%)$ & $-18.49 \pm 5.41$ & $-21.13 \pm 2.62$ & $-16.4 \pm 4.1$ & 0.1989 & 0.4579 & $0.0039 *$ \\
\hline
\end{tabular}

Data are shown as average \pm standard deviation. $\mathrm{P}$ value by two-way ANOVA test. $\mathrm{C}=$ control group; G5D=dialyzed patients group; $\mathrm{G2}-3 \mathrm{~T}=$ patients after renal transplantation group; $\mathrm{EDV}=$ end-diastolic volume; $E D V I=E n d$-diastolic volume index; $E F=e j e c t i o n$ fraction; $\mathrm{LV}=$ left ventricle; $\mathrm{GLS}=$ global longitudinal strain

Table 5. ABI in end-stage kidney disease patients compared to control group

\begin{tabular}{|c|c|c|c|c|c|c|}
\hline Parameter & G5D & G2-3T & Control & $\begin{array}{c}\text { G5D } \\
\text { vs } \\
\text { G2-3T } \\
\text { p-value }\end{array}$ & $\begin{array}{c}\text { G5D } \\
\text { vs } \\
\text { control } \\
\text { p-value }\end{array}$ & $\begin{array}{c}\text { G2-3T } \\
\text { vs } \\
\text { control } \\
\text { p-value }\end{array}$ \\
\hline$A B I$ & $1.072 \pm 0.11$ & $1.039 \pm 0.08$ & $1.054 \pm 0.10$ & 0.7324 & 0.9841 & 0.9075 \\
\hline
\end{tabular}

Data are shown as average \pm standard deviation. P-value by 2 way ANOVA test.

In end-stage kidney disease patients, the optimal set of echocardiographic parameters to assess cardiac morphology and functions is still not defined. The realtime 3D echocardiography has not been studied extensively despite its possible benefits in accuracy and convenience (GLS calculated from a single image). In our study, the end-stage patients, dialyzed (G5D) as well as after kidney transplantation (G2-3T), compared with the control group, showed worsened cardiac structure increased LVMI, end-diastolic volume (EDV), EDV index and 3D LV mass index. In contrast, diastolic cardiac function parameters (E/e'ratio, RVSP) shown no significant differences between the control and both endstage groups. However, systolic function parameters (derived from 3D) were better after transplantation (G2-3T group), GLS was significantly more negative, and ejection fraction calculated from $3 \mathrm{D}$ was nonsignificantly higher. These differences in systolic parameters suggest the possibility of improved systolic function in G2-3T patients. Also the study with end-stage CKD patients before and after transplantation (12 to 24 months), significant improvements of cardiac structure and function were reported in LVEDD, LV mass, RVSP and EF in patients with LV dysfunction (Hayer et al.
2019, Hewing et al. 2016). Nevertheless, these changes in cardiac structure and function might be limited in patients with cardiovascular comorbidities (Kobayashi et al. 2020). Therefore, 3D echocardiographic parameters appear to be more sensitive in assessing the cardiac changes induced by kidney transplantation.

Left ventricular hypertrophy is one of the common findings in CKD patients, affecting up to $75 \%$ of end-stage patients (Park, et al. 2012). Also, concentric hypertrophy was significantly associated with progression to dialysis in patients with CKD stage 3-5 (Chen SC, et al. 2011). Also, inappropriate LV mass is a negative prognostic factor for $\mathrm{CV}$ outcomes and mortality (deSimone et al. 2001, Chen 2012, Paoletti et al. 2011), and is strongly associated with the presence and severity of CKD (Chen et al. 2011, Nardi et al. 2009). Successful kidney transplantation was reported to lead to ventricular hypertrophy regression (Dudziak et al. 2005, Hawwa et al. 2015, Hewing et al. 2016, Jhinger et al. 2021). However, several Cardiac magnetic resonance (CMR) studies have shown no significant change in LV mass after transplantation (Hayer et al. 2019, Patel et al. 2008). Our results of higher LVMI and 3D LVMI comply with previous echocardiography 
studies. However, the proportion of concentric hypertrophy (12.2\%) was smaller compared to previous larger studies (Matsushita et al. 2015), indicating the lower prevalence of arterial hypertension in our study population. Notably, there was a consistent tendency towards lower LV mass in 3D measurement compared to 2D. Further improvement might also be possible with LV mass cut-off values recommendation specific for 3D measurement. Most studies that have investigated the association between CKD and cardiac remodeling have assessed LV mass or hypertrophy but did not evaluate measures of LV size and volume. In end-stage CKD patients, end-diastolic volume can be dependent on hydration status, therefore, could be decreased by recent hemodialysis. The results of CMR studies were conflicting showing reduced EDV (Hayer et al. 2019, Prasad et al. 2018) or reported no significant difference (Patel et al. 2008). Our results indicate that LV dilatation parameters obtained by 3D echocardiography can be utilized in the cardiac evaluation of end-stage CKD. EDVI appears to be the most sensitive parameter to assess LV structure, out of the used parameters. Although the difference in EDVI between G5D and G2-3T was not significant, there was a slight trend towards lower EDVI in G2-3T, whereas the differences in the other volumetric parameters, as well as both $2 \mathrm{D}$ and $3 \mathrm{D}$ LVMI, were negligible. This result of the more prominent difference in EDV compared to LVMI in patients after transplantation are comparable to the results of previous CMR studies (Hayer et al. 2019, Prasad et al. 2018).

In CKD patients, changes in LV morphology lead to impaired relaxation and increased chamber stiffness, thus increasing cardiac filling pressures, thereby increasing the efferent renal pressure and this, in turn, leads to progressive decline in renal function (Halley et al. 2011). The ratio of trans mitral $\mathrm{E}$ wave velocity (E) to early diastolic mitral velocity (e'), E/e' has been associated with $\mathrm{LV}$ diastolic function and is used as an estimate of LV filling pressure (Park et al. 2011). In ESRD patients the ratio of E/e' $\geq 15$ predicted an increase in LV filling pressure with a sensitivity of $82 \%$ and specificity of $88 \%$, and was associated with an increased risk of mortality. Higher E/e' ratio was found in patients with more rapid progression of CKD and was associated with an increased risk of starting dialysis (Chen SC et al. 2013). In this study, diastolic dysfunction classified by the grade or represented by the $\mathrm{E} / \mathrm{e}^{\prime}$ ratio was more frequent in G5D group compared to G2-3T and control. This is in line with previous studies that reported unchanged or even worsened diastolic function after transplantation, despite improved LV geometry and systolic function (Dudziak et al. 2005).

Although most CKD patients have preserved ejection fraction ( $\geq 50 \%$ ) (Matsushita et al. 2017), LV systolic dysfunction has been reported to be an important risk factor for $\mathrm{CV}$ death end-stage patients (Foley et al. 2000). In a longitudinal study, LV ejection was significantly worse in patients who initiated dialysis therapy and was associated with a greater risk of mortality (Bansal et al. 2018). In a large renal insufficiency cohort study, reduced kidney function was associated with abnormal cardiac structure, however, no association was found between kidney function and systolic or diastolic dysfunction (defined as ejection fraction < $45 \%$ ) (Park et al. 2012). Consistent with previous studies, a normal ejection fraction of the left ventricle was observed in the G5D and G2-3T groups, not significantly different from the control group. In opposite, most of the recent echocardiographic studies have found improved ejection fraction after kidney transplantation (Hawwa et al. 2015, Jhinger et al. 2021, Yilmaz et al. 2020). Improved ejection was also observed in a CMR study by Hayer et al. (Hayer et al. 2019), however previous CMR studies have found no significant difference in EF (Patel et al. 2008). In the present study, we observed only non-significantly higher ejection fraction in transplanted patients (G2-3T group) compared to dialyzed patients (G5D group), in compliance with the previous study by Hawwa et al. in which the improvement was only significant in patients with at least moderately reduced LV systolic function (Hawwa et al. 2015).

The end-stage CKG patients are characterized by a high prevalence of peripheral artery disease, an important manifestation of systemic atherosclerosis. The ABI (ankle-brachial index) is a common noninvasive and useful screening test for detecting peripheral artery disease. The clinical implications of ABI cut-points are not well defined in patients with CKD despite the increased prevalence of high $\mathrm{ABI}(>1.3)$ attributed to arterial stiffness caused by vascular calcification in peripheral and distal medial arteries. However, previously reported studies have shown, that the sensitivity of ABI $<0.9$ for detecting peripheral artery disease in hemodialysis patients was only $29.9 \%$ (specificity was $100 \%$ ) (Liu et al. 2011). However, in our study, ABI values measured in all groups, including G5D, G2-3T and control group, were within the normal range. In patients 
with CKD, mainly, in the diabetic population, the presence of calcified incompressible vessels based on medial arterial calcinosis may lead to falsely higher ABI values and incorrect classification.

The major limitation of the study is the relatively small sample size, as narrowly specified patients undergoing dialysis and kidney transplantation are included. Although some significant differences in LV structure and function were observed, we believe more differences would be recorded with a larger study population. In addition, especially in evaluating changes after kidney transplantation, a longitudinal study, optimally with a long-term follow-up, could yield more significant differences, as well as prognostic assessment. Moreover, the timing of echocardiograms after the transplantation varied considerably.

\section{Conclusions}

The novelty of this study is to utilize the $3 \mathrm{D}$ echocardiographic parameters that are normally used in LV assessment, to compare patients in different stages of CKD, 3D echocardiography appears to be more sensitive than 2D echocardiography in the assessment of myocardial structure and function in CKD patients. In end-stage CKD patients, changes in cardiac structure, rather than function, seems to be more pronounced as are 3D derived end-diastolic volume and LV mass indexed for body surface appears to have deteriorated in dialyzed and transplanted patients. In 2D echocardiography, myocardial mass represented by LVMI appears to be a more sensitive marker of cardiac structural changes. We observed the favorable impact of kidney transplantation on cardiac structure and function; however, the differences were non-significant. The improvement seems to be more pronounced in cardiac function parameters - (E/e', 3D LV EF and GLS). We conclude that the ankle-brachial index is not an appropriate screening test to determine the cardiovascular risk in endstage kidney disease patients.

\section{Abbreviations}

ABI, ankle-brachial index; ACR, albumin-to-creatinine ratio; AER, albumin excretion rate; ASE, American Society of Echocardiography; BMI, body mass index; BSA, body surface area; CKD, chronic kidney disease; $\mathrm{CMR}$, Cardiac magnetic resonance; $\mathrm{CV}$, cardiovascular E/e', peak early diastolic velocity/average peak early diastolic velocity of mitral valve annulus; EACVI, European Association of Cardiovascular Imaging; EDV, end-diastolic volume; EF, ejection fraction; eGFR, estimated glomerular filtration rate; ESRD, end-stage renal disease; GFR, glomerular filtration rate; GLS, global longitudinal strain; HDL, high-density lipoprotein; IVS, interventricular septum; KDIGO, Kidney Disease Improving Global Outcomes; LA, left atrial; LAVI, left atrial volume index; LDL, low-density lipoprotein; LV, left ventricular; LV EF, left ventricle ejection fraction; LVEDD, left ventricle and diastolic diameter; LVEDDI, left ventricle and diastolic diameter index; LVH, Left ventricle hypertrophy; LVMI, left ventricular mass/body surface area index; PWd, posterior wall; RVSP, Right ventricular systolic pressure; RWT, relative wall thickness; TAG, triacylglycerols

\section{References}

ANDRASSY KM: Comments on 'KDIGO 2012 clinical practice guideline for the evaluation and management of chronic kidney disease'. Kidney Int 84: 622-623, 2013. https://doi.org/10.1038/ki.2013.243

BANSAL N, ROY J, CHEN H-Y, DEO R, DOBRE M, FISCHER MJ, FOSTER E, GO AS, HE J, KEANE MG: Evolution of echocardiographic measures of cardiac disease from CKD to ESRD and risk of all-cause mortality: findings from the CRIC study. Am J Kidney Dis 72: 390-399, 2018. https://doi.org/10.1053/j.ajkd.2018.02.363

BHATTI NK, GALOUGAHI KK, PAZ Y, NAZIF T, MOSES JW, LEON MB, STONE GW, KIRTANE AJ, KARMPALIOTIS D, BOKHARI S, HARDY MA, DUBE G, MOHAN S, RATNER LE, COHEN DJ, ALI ZA: Diagnosis and management of cardiovascular disease in advanced and end-stage renal disease. $\mathrm{J}$ Am Heart Assoc 5: e003648, 2016. https://doi.org/10.1161/JAHA.116.003648

BYOUNG-GEUN H, YOUNG LJ, CHOI SO, JAE-WON Y, JAE-SEOK K: Relative overhydration is independently associated with left ventricular hypertrophy in dialysis naïve patients with stage 5 chronic kidney disease. Sci Rep 10: 2020. https://doi.org/10.1038/s41598-020-73038-8 
DESIMONE G, PALMIERI V, KOREN MJ, MENSAH GA, ROMAN MJ, DEVEREUX RB: Prognostic implications of the compensatory nature of left ventricular mass in arterial hypertension. J Hypert 19: 119-125, 2001. https://doi.org/10.1097/00004872-200101000-00016

DEFERRARI G, CIPRIANI A, LA PORTA E: Renal dysfunction in cardiovascular diseases and its consequences. J Nephrol 34: 137-153, 2021. https://doi.org/10.1007/s40620-020-00842-w

DU BOIS D, DU BOIS EF: Clinical calorimetry: tenth paper a formula to estimate the approximate surface area if height and weight be known. Archives Int Med XVII: 863-871, 1916. https://doi.org/10.1001/archinte.1916.00080130010002

DUDZIAK M, DĘBSKA-ŚLIZIEŃ A, RUTKOWSKI B: Cardiovascular effects of successful renal transplantation: a 30-month study on left ventricular morphology, systolic and diastolic functions. Transplant Proc 37 : 1039-1043, 2005. https://doi.org/10.1016/j.transproceed.2004.12.201

FOLEY RN, PARFREY PS, KENT GM, HARNETT JD, MURRAY DC, BARRE PE: Serial change in echocardiographic parameters and cardiac failure in end-stage renal disease. J Am Soc Nephrol 11: 912-916, 2000. https://doi.org/10.1681/ASN.V115912

GERHARD-HERMAN MARIE D, GORNIK HEATHER L, BARRETT C, BARSHES NEAL R, CORRIERE MATTHEW A, DRACHMAN DOUGLAS E, FLEISHER LEE A, FOWKES FRANCIS GERRY R, HAMBURG NAOMI M, KINLAY S, LOOKSTEIN R, MISRA S, MUREEBE L, OLIN JEFFREY W, PATEL RAJAN AG, REGENSTEINER JUDITH G, SCHANZER A, SHISHEHBOR MEHDI H, STEWART KERRY J, TREAT-JACOBSON D, WALSH ME: 2016 AHA/ACC guideline on the management of patients with lower extremity peripheral artery disease: executive summary: a report of the american college of cardiology/american heart association task force on clinical practice guidelines. Circulation 135: e686-e725, 2017. https://doi.org/10.1161/CIR.0000000000000470

HALLEY CM, HOUGHTALING PL, KHALIL MK, THOMAS JD, JABER WA: Mortality rate in patients with diastolic dysfunction and normal systolic function. Arch Inter Med 171: 1082-1087, 2011. https://doi.org/10.1001/archinternmed.2011.244

HAWWA N, SHRESTHA K, HAMMADAH M, YEO PSD, FATICA R, TANG WW: Reverse remodeling and prognosis following kidney transplantation in contemporary patients with cardiac dysfunction. J Am Coll Cardiol 66: 1779-1787, 2015. https://doi.org/10.1016/j.jacc.2015.08.023

HAYER MK, RADHAKRISHNAN A, PRICE AM, BAIG S, LIU B, FERRO CJ, CAPTUR G, TOWNEND JN, MOON JC, EDWARDS NC: Early effects of kidney transplantation on the heart-a cardiac magnetic resonance multi-parametric study. Int J Cardiol 293: 272-277, 2019. https://doi.org/10.1016/j.ijcard.2019.06.007

HEWING B, DEHN AM, STAECK O, KNEBEL F, SPETHMANN S, STANGL K, BAUMANN G, DREGER H, BUDDE K, HALLECK F: Improved left ventricular structure and function after successful kidney transplantation. Kidney Blood Press Res 41: 701-709, 2016. https://doi.org/10.1159/000450559

CHEN F-A, YANG C-Y, YANG W-C, CHEN J-Y, NG Y-Y, LI S-Y, LIU W-S, CHENG S-T, WANG Y-J, LIN C-C: Ankle-brachial index is a powerful predictor of renal outcome and cardiovascular events in patients with chronic kidney disease. Sci World J 2012: 238494, 2012. https://doi.org/10.1100/2012/238494

CHEN S-C, CHANG J-M, LIU W-C, CHEN Y-Y, CHEN L-I, HUANG J-C, YANG T-K, SU H-M, CHEN H-C: The ratio of observed to predicted left ventricular mass is independently associated with increased cardiovascular events in patients with chronic kidney disease. Hypert Res 35: 832-838, 2012. https://doi.org/10.1038/hr.2012.40

CHEN S-C, CHANG J-M, TSAI Y-C, HUANG J-C, CHEN L-I, SU H-M, HWANG S-J, CHEN H-C: Ratio of transmitral E-wave velocity to early diastole mitral annulus velocity with cardiovascular and renal outcomes in chronic kidney disease. Nephron Clin Practice 123: 52-60, 2013. https://doi.org/10.1159/000351513

CHEN S-C, SU H-M, HUNG C-C, CHANG J-M, LIU W-C, TSAI J-C, LIN M-Y, HWANG S-J, CHEN H-C: Echocardiographic parameters are independently associated with rate of renal function decline and progression to dialysis in patients with chronic kidney disease. Clin J Am Soc Nephrol 6: 2750-2758, 2011. https://doi.org/10.2215/CJN.04660511 
JHINGER MK, SOHAL PM, MAKKAR V, TONDON R, WANDER GS, SANDHU JS: Changes in cardiac structure and function before and after renal transplantation: a longitudinal study. Transplant Proc 53:1014-1018, 2021. https://doi.org/10.1016/j.transproceed.2021.01.026

KOBAYASHI M, HUTTIN O, SCHIKOWSKI J, BOZEC E, ZOHRA L, FRIMAT L, GIRERD N, GIRERD S: Cardiovascular comorbidities are the main predictors of cardiac reverse remodeling following kidney transplantation. Cardiology 145: 71-76, 2020. https://doi.org/10.1159/000504381

LANG RM, BADANO LP, MOR-AVI V, AFILALO J, ARMSTRONG A, ERNANDE L, FLACHSKAMPF FA, FOSTER E, GOLDSTEIN SA, KUZNETSOVA T: Recommendations for cardiac chamber quantification by echocardiography in adults: an update from the American Society of Echocardiography and the European Association of Cardiovascular Imaging. Eur Heart J Cardiovasc Imaging 16: 233-271, 2015. https://doi.org/10.1093/ehjci/jev014

LIU Y-W, SU C-T, HUANG Y-Y, YANG C-S, HUANG J-W, YANG M-T, CHEN J-H, TSAI W-C: Left ventricular systolic strain in chronic kidney disease and hemodialysis patients. Am J Nephrol 33: 84-90, 2011. https://doi.org/10.1159/000322709

MAILLOUX LU, HALEY WE: Hypertension in the ESRD patient: pathophysiology, therapy, outcomes, and future directions. Am J Kidney Dis 32: 705-719, 1998. https://doi.org/10.1016/S0272-6386(98)70146-5

MALÍK J, DANZIG V, BEDNÁŘOVÁ V, HRUŠKOVÁ Z: Echocardiography in patients with chronic kidney diseases. Cor et Vasa 60: e287-e295, 2018. https://doi.org/10.1016/j.crvasa.2017.07.008

MATSUSHITA K, CORESH J, SANG Y, CHALMERS J, FOX C, GUALLAR E, JAFAR T, JASSAL SK, LANDMAN GW, MUNTNER P: Estimated glomerular filtration rate and albuminuria for prediction of cardiovascular outcomes: a collaborative meta-analysis of individual participant data. Lancet Diab Endocrinol 3: 514-525, 2015. https://doi.org/10.1016/S2213-8587(15)00040-6

MATSUSHITA K, KWAK L, SANG Y, BALLEW SH, SKALI H, SHAH AM, CORESH J, SOLOMON S: Kidney disease measures and left ventricular structure and function: the atherosclerosis risk in communities study. J Am Heart Assoc 6: e006259, 2017. https://doi.org/10.1161/JAHA.117.006259

Nagueh S, Smiseth O, Appleton C, Byrd B, Dokainish H, Edvardsen T. ASE/EACVI Guidelines and Standards. Recommendations for the evaluation of left ventricular diastolic function by echocardiography: An update from the American Society of Echocardiography and the European Association of Cardiovascular Imaging. J Am Soc Echocardiogr 29: 277-314, 2016. https://doi.org/10.1016/j.echo.2016.01.011

NARDI E, PALERMO A, MULE G, CUSIMANO P, COTTONE S, CERASOLA G: Left ventricular hypertrophy and geometry in hypertensive patients with chronic kidney disease. J Hypertens 27: 633-641, 2009. https://doi.org/10.1097/HJH.0b013e3283220ecd

PAOLETTI E, BELLINO D, GALLINA AM, AMIDONE M, CASSOTTANA P, CANNELLA G: Is left ventricular hypertrophy a powerful predictor of progression to dialysis in chronic kidney disease? Nephrol Dial Transplant 26: 670-677, 2011. https://doi.org/10.1093/ndt/gfq409

PARK J-H, MARWICK TH: Use and limitations of E/e'to assess left ventricular filling pressure by echocardiography. J Cardiovasc Ultrasound 19: 169, 2011. https://doi.org/10.4250/jcu.2011.19.4.169

PARK M, HSU C-Y, LI Y, MISHRA RK, KEANE M, ROSAS SE, DRIES D, XIE D, CHEN J, HE J: Associations between kidney function and subclinical cardiac abnormalities in CKD. JASN 23: 1725-1734, 2012. https://doi.org/10.1681/ASN.2012020145

PATEL RK, MARK PB, JOHNSTON N, MCGREGOR E, DARGIE HJ, JARDINE AG: Renal transplantation is not associated with regression of left ventricular hypertrophy: a magnetic resonance study. Clin J Am Soc Nephrol 3: 1807-1811, 2008. https://doi.org/10.2215/CJN.01400308

PRASAD GR, YAN AT, NASH MM, KIM SJ, WALD R, WALD R, LOK C, GUNARATNAM L, KARUR GR, KIRPALANI A: Determinants of left ventricular characteristics assessed by cardiac magnetic resonance imaging and cardiovascular biomarkers related to kidney transplantation. Can J Kidney Health Dis 5: 2054358118809974, 2018. https://doi.org/10.1177/2054358118809974 
RANGASWAMI J, MATHEW RO, PARASURAMAN R, TANTISATTAMO E, LUBETZKY M, RAO S, YAQUB MS, BIRDWELL KA, BENNETT W, DALAL P, KAPOOR R, LERMA EV, LERMAN M, MCCORMICK N, BANGALORE S, MCCULLOUGH PA, DADHANIA DM, Workgroup obotASoTsK-PCoPCD: Cardiovascular disease in the kidney transplant recipient: epidemiology, diagnosis and management strategies. Nephrol Dial Transplant 34: 760-773, 2019. https://doi.org/10.1093/ndt/gfz053

RUDSKI LG, LAI WW, AFILALO J, HUA L, HANDSCHUMACHER MD, CHANDRASEKARAN K, SOLOMON SD, LOUIE EK, SCHILLER NB: Guidelines for the echocardiographic assessment of the right heart in adults: a report from the American Society of Echocardiography: endorsed by the European Association of Echocardiography, a registered branch of the European Society of Cardiology, and the Canadian Society of Echocardiography. JASE 23: 685-713, 2010. https://doi.org/10.1016/j.echo.2010.05.010

YILMAZ KC, AKGUN AN, KESKIN S, CIFTCI O, MORAY G, MUDERRISOGLU H, HABERAL M: The effect of renal transplantation on cardiac functions. Saudi J Kidney Dis Transpl 31: 1051-1056, 2020. https://doi.org/10.4103/1319-2442.301170 